\title{
Disiplin Pegawai Untuk Peningkatan Kinerja Di Balai Latihan Masyarakat Pekanbaru
}

\author{
${ }^{1}$ Weli Erayuana, ${ }^{2}$ Seno Andri, ${ }^{3}$ Febri Yuliani \\ 1Program Studi Ilmu Hukum Universitas Riau, Indonesia \\ ${ }^{2}$ Program Studi Ilmu Administrasi Publik Universitas Riau, Indonesia \\ 3Program Studi Ekonomi Pembangunan Universitas Riau, Indonesia \\ e-mail: weliyuana84@yahoo.com
}

\begin{abstract}
Abstrak
Tujuan penelitian ini mendeskripsikan masalah kedisiplinan Pegawai Balai Latihan Masyarakat Pekanbaru dalam dalam peningkatan kinerja dengan penggunaan finger print. Kedisiplinan yang digambarkan berkaitan dengan kedisiplinan waktu, disiplin mengikuti aturan, disiplin dengan tanggungjawab. Penelitian ini mengunakan metode penelitian kualitatif pendekatan deskriptif untuk mengambarkan kedisiplinan pegawai. Fokus penelitian ini pada disiplin pegawai dalam meningkatkan kinerja organisasi. Informan Penelitian diambil mengunakan teknik purposive sampling karena peneliti sudah mengetahui lokasi dan informan penelitian dengan data-data yang bersifat komunitas dari subjektif. Informan penelitian terdiri dari Bendaharawan, Administrator atau operator dari Finger Print Bagian Sistem Informasi, Bagian Program Perencanaan Kinerja Pegawai dan Pegawai Balai Latihan Masyarakat Kota Pekanbaru. Jenis dan sumber data dalam penelitian ini mengunakan data primer terdiri dari data yang diperoleh secara langsung dari lapangan sedangkan data sekunder diperoleh data yang diperoleh dari literature review dan dokumen administrasi yang dipublikasi atau tidak dipublikaan. Teknik pengumpulan data yang digunakan. Teknik pengumpulan data dengan observasi, wawancara, dan dokumentasi. Analisis data yang digunakan dengan dengan model Interaktif dan dalam menguji validitas data dengan triagulasi data. Hasil penelitian menunjukkan dispilin pegawai tidak berjalan sesuai dengan aturan dan harapan dalam pencapaian kinerja organisasi.
\end{abstract}

Keywords: Inovasi, Pelayanan Publik, Informasi, Kepala Desa, Pemerintahan Desa.

\section{Abstract}

The purpose of this study is to describe the discipline problems of Pekanbaru Community Training Center Employees in improving performance by using finger print. Discipline is described related to time discipline, discipline follows the rules, discipline with responsibility. This study uses descriptive qualitative research methods to describe employee discipline. The focus of this research is on employee discipline in improving organizational performance. Research informants were taken using purposive sampling technique because researchers already knew the location and research informants with community data from the subjective. The research informants consisted of Treasurers, Administrators or Operators from the Finger Print Information System Section, Employee Performance Planning Program Section and the Pekanbaru City Community Training Center Employees. Types and sources of data in this study use primary data consisting of data obtained directly from the field while secondary data obtained from data literature review and administration documents published or not published. Data collection techniques used. Data collection techniques with observation, interviews, and documentation. Analysis of the data used with the Interactive model and in testing the validity of the data with data triagulation. The results showed employee discipline not working according to the rules and expectations in achieving organizational performance.

Kata Kunci : Innovation. Public Services, Informations, a village head, village government. 


\section{PENDAHULUAN}

Kementerian Desa, Pembangunan Daerah Tertinggal dan Transmigrasi (Kemendes PDTT) Mempunyai tugas menyelenggarakan urusan pemerintahan di bidang pembangunan desa dan kawasan perdesaan, percepatan pembangunan daerah tertinggal dan transmigrasi mengeser tugas dan fungsi dari Direktorat Jenderal Pembinaan, Pendidikan, Pelatihan dan Produktivitas Kementerian Tenaga Kerja dan Transmigrasi ke Badan Penelitian dan Pengembangan, Pendidikan dan Pelatihan dan Informasi Kementerian Desa, Pembangunan Daerah Tertinggal dan Transmigrasi dengan Peraturan Kemendes PDTT Nomor 9 Tahun 2015 tanggal 19 Juni 2015 tentang Organisasi dan Tata Kerja Unit Pelaksanaan Teknis di Lingkungan Kementerian Desa, Pembangunan Daerah Tertinggal dan Transmigrasi, Balai Latihan Masyarakat Pekanbaru semula adalah Unit Pelaksanaan Teknis di bidang pelatihan transmigrasi yang wilayah kerjanya mencakup 7 provinsi yang ada di Sumatera, berubah menjadi Balai Latihan Masyarakat dengan wilayah kerja provinsi Aceh, Sumatera Utara, Sumatera Barat, Riau, Kepulauan Riau, Jambi dan Bengkulu, yang di dalam pelaksanaan tugasnya bertanggung jawab secara administrative maupun secara teknis kepada Badan Penelitian dan Pengembangan, Pendidikan dan Pelatihan, dan Informasi Republik Indonesia. Secara hirarki Balai Latihan Masyarakat Pekanbaru berada di bawah perpanjangan tangan dan bertanggung jawab kepada Badan Penelitian dan Pendidikan dan Pelatihan, dan Informasi Kemendes PDTT. Balai Latihan Masyarakat Pekanbaru Mempunyai tugas melaksanakan pelatihan masyarakat, pengelolaan data dan sistem informasi serta kerja sama di bidang desa, daerah tertinggal, daerah tertentu dan transmigrasi.

Pada tahun 2018 Balai Latihan Masyarakat Pekanbaru sesuai perubahan kebijakan (refocusing) melakukan langkah - langkah strategis di dalam rangka percepatan penyerapan anggaran, agar sasaran strategis dan indikator kerja utama dapat tercapai maka ditetapkan kinerja tahun 2018 dalam LAKIP (tabel 1):

Tabel 1 Penetapan Kinerja dalam Lakip 2018

\begin{tabular}{|c|c|c|c|}
\hline \multirow{2}{*}{$\begin{array}{c}\text { SASARAN } \\
\text { STRATEGIS }\end{array}$} & \multirow[b]{2}{*}{ INDIKATOR KINERJA } & \multicolumn{2}{|c|}{ TARGET } \\
\hline & & SEMULA & MENJADI \\
\hline \multirow{4}{*}{$\begin{array}{l}\text { Masyarakat yang } \\
\text { mengikuti pelatihan } \\
\text { dalam pembangunan } \\
\text { desa, daerah tertinggal } \\
\text { dan transmigrasi }\end{array}$} & $\begin{array}{l}\text { 1. Jumlah masyarakat dan kader } \\
\text { pemberdayaan masyarakat yang } \\
\text { mendapat pelatihan }\end{array}$ & 2.145 orang & 2.665 orang \\
\hline & $\begin{array}{l}\text { 2. Jumlah dukungan manajemen } \\
\text { satker }\end{array}$ & 5 Layanan & 4 Layanan \\
\hline & $\begin{array}{l}\text { 3. Jumlah layanan internal } \\
\text { (Overhead) }\end{array}$ & 2 Layanan & 2 Layanan \\
\hline & 4. Jumlah layanan perkantoran & 12 Bulan & 12 Bulan \\
\hline
\end{tabular}

Sumber Data : Lakip Balai Latihan Masyarakat Pekanbaru 2018

Dalam mencapai kinerja Balai Latihan Masyarakat Pekanbaru dibutuhkan ketersediaan personil yang secara kuantitas dan kualitas belum sangat memadai. Keterbatasan jumlah personil terutama bagi tenaga pemandu bidang pelatihan masyarakat (PSM) masih menjadi suatu kendala yang cukup berpengaruh bagi Balai Latihan Masyarakat Pekanbaru. Keterbatasan personil ini membutuhkan kedisiplinan pegawai yang ada, untuk meningkatkan kedisiplinan itu maka Balai Latihan Masyarakat Pekanbaru memberlakukan Absensi Sidik Jari (Finger Print) sebagai bukti kehadiran pegawai (absensi) bisa di dapatkan melalui alat agar membantu visi dari sumber daya manusia untuk mengevaluasikan kinerja para pegawai yang berkompeten. Penerapan absensi Finger Print diterapkan kepada pegawai Kementerian Desa Pembangunan Daerah Tertinggal dan Transmigrasi Balai Latihan Masyarakat 
Pekanbaru sejak tahun 2012, dimana dari hasil penerapan absensi Finger Print tersebut memiliki pengaruh yang baik, sehingga sebagian besar tidak ada lagi pegawai yang datang terlambat atau korupsi waktu dan tidak ada lagi menitip absen kepada pegawai yang lainnya, oleh karena itu peralatan ini hanya merekam sidik jari pegawai yang bersangkutan, selain itu peralatan ini bekerja online dan dapat dipantau melalui computer yang terhubung dengan peralatan tersebut. Finger Print ini juga memudahkan bagi operator merekap atau menginput data absensi para pegawai, yang dulunya secara manual sekarang sudah lebih instan dan mudah.

Dengan adanya Finger Print akan meningkatkan disiplin pegawai yang berpangaruh positif terhadap kinerja pegawai (Kumarayati, Suparta, \& Yasa, 2017) namun fenomena menunjukkan Sistem absensi berbasis online menggunakan Finger Print dan terintegrasi dengan SKP PNS yang dapat mempengaruhi besar atau kecilnya penghasilan Remunerasi tidak mempengaruhi kinerja karena masih ditemukan pegawai yang beristirahat disaat jam kerja yang dilakukan disaat pimpinan sedang berada diluar kota atau dinas luar selain itu pegawai keluar kantor atau ke kantin dengan alasan sarapan pagi pada jam kerja sehingga bisa memakan jam kerja dikantin dan bukti pada daftar catatan keluar masuk satpam dipintu keluar.

Penelitian terdahulu (Yudiastra \& Darma, 2015) menyatakan bahwa pengunaan finger print sebagai alat informasi teknologi berpengaruh terhadap kinerja, insentif, disiplin pegawai. Selain itu memang dalam meningkatkan disiplin pegawai dibutuhkan peran pemimpin baik melaksanakan fungsi kepemimpinannya, pemberian insentif serta pengawasan (Rasyidi, Paranoan, \& Djumlani, 2013) ini sesuai dengan hasil kajian (Saputra, Marlinda, \& Sufi, 2016) bahwa kepemimpinan akan berpenagruh positif. Fenomena lain pada penelitian yang menarik adanya operator menginput data Finger Print tersebut tidak jujur temuan pimpinan langsung saat operator terlambat masuk kerja. Berdasarkan fenomena dan kajian terdahulu maka peneliti akan mengangkat kedisiplinan pegawai ini dengan melakukan kajian Disiplin Pegawai di Balai Latihan Masyarakat Pekanbaru.

\section{METODE}

Penelitian ini mengunakan metode penelitian kualitatif pendekatan deskriptif untuk mengambarkan kedisiplinan pegawai. Lokasi penelitian ini dilakukan di Kantor Balai Latihan Masyarakat Pekanbaru. Fokus penelitian ini pada disiplin pegawai dalam meningkatkan kinerja dan remunerasi. Sedangkan Informan Penelitian mengunakan teknik purposive sampling karena peneliti sudah mengetahui lokasi dan informan penelitian dengan data-data yang bersifat komunitas dari subjektif. Informan penelitian terdiri dari Bendaharawan, Administrator atau operator dari Finger Print Bagian Sistem Informasi, Bagian Program Perencanaan Kinerja Pegawai dan Pegawai Balai Latihan Masyarakat Kota Pekanbaru.

Jenis dan sumber data dalam penelitian ini mengunakan data primer terdiri dari data yang diperoleh secara langsung dari lapangan sedangkan data sekunder diperoleh data yang diperoleh dari literature review dan dokumen administrasi yang dipublikasi atau tidak dipublikaan. Teknik pengumpulan data yang digunakan. Teknik pengumpulan data dengan observasi, wawancara, dan dokumentasi. Analisis data yang digunakan dengan dengan model Interaktif dan dalam menguji validitas data dengan triagulasi data. 


\section{HASIL DAN PEMBAHASAN}

Disiplin adalah rasa taat dan patuh terhadap nilai yang dipercatat dan menjadi tanggung jawabnya, dalam Birokrasi berarti patuh kepada peraturan atau tunduk pada pengawasan dan pengendalian. Sedangkan pendisiplinan adalah sebuah usaha yang dilaksanakan untuk menanamkan nilai atau pemaksaan supaya subjek mentaati sebuah peraturan. Tujuan organisasi yang harus segera dibangun dan ditegakkan adalah kedisiplinan pegawai yang merupakan kunci keberhasilan suatu organisasi dalam mencapai tujuan dengan cerminan berupa besarnya tanggung jawab seseorang terhadap tugas-tugas yang diberikan kepadanya yang mendorong gairah kerja, semangat kerja, dan terwujudnya tujuan organisasi. Dengan adanya teknologi akan mengubah motivasi, disiplin pegawai dalam meningkatkan kinerja, (Setiawan \& Yulianti, 2018) menyatakan bahwa dengan adanya finger print memberikan pengaruh yang kuat terhadap peningkatan kedisiplin pegawai dan berdampak kepada peningkatan kinerja. Namun dalam hasil penelitian menunjukkan bahwa Absensi finger print tidak meningkatkan kinerja dan motivasi pegawai karena masih ditemukan pekerjaan yang diberikan menjadi tertunda dan bertumpuk." (Wawancara dengan staf bidang program pengelolaan data dan sistem informasi, Bapak Pius Siahaan tanggal 20 September 2019).

Padahal Penerapan finger print juga berdapak pada remunerasi Pegawai dihitung melalui Absensi Finger Print tersebut sekitar 60 \% dan dari Lembar Kerja Harian (LKH) Pegawai setiap harinya sekitar 40 $\%$. Apabila pegawai melanggar peraturan pendiplinan waktu maka dari itu akan dipotong sesuai keterlambatan waktunya. Misalnya Pegawai masuk pada senin sampai kamis pukul 07.30 WIB dan pulangnya pukul 16.00 WIB, sedangkan di hari jum'at pukul 07.30 WIB pulangnya Pukul 16.00 WIB, ada waktu masa toleransi atau penggantian jam keterlambatan sekitar 30 menit dan apabila ASN terlambat dan masuk pukul 08.01 sudah dikategorikan dalam keterlambatan dan akan dipotong sekitar 0.5 $\%$ lewat dari peraturan yang telah ditetapkan maka Pegawai akan dikenakan potongan. (Wawancara dengan Bendaharawan Keuangan Ibu Yulisbert Maria Simanggungsong,SE tanggal 20 September 2019).

Disiplin menurut Veithzal Rivai dalam (Zahari, 2014) adalah alat untuk komunikasi pimpinan agar pegawai bersedia mengubah perilakunya sebagai upaya meningkatkan kesadaran, kesediaan memmatuhi norma-norma yang berlaku dengan indikator kehadiran, ketaatan kepada aturan kerja, ketaatan pada standar kerja, tingkat kewaspadaan tinggi, bekerja etis. Temuan penelitian menunjukkan PNS dalam memandang kehadiran hanya sebagai mengisi daftar hadir,tidak merupakan proses proses mengubah perilaku yang sadar dan sesai aturan. Selain itu dalam ketaatan kerja berdasarkan standar pegawai tidak berpedoman dalam mencapai kinerjanya karena banyaknya pekerjaan yang tidak siap pada waktu dan standar yang telah ditentukan. Kewaspadaan tinggi pegawai dalam menjaga organisasi juga belum berjalan optimal karena pegawai masih ditemukan masih keluar dari kantor dengan alasan ke kantin, belanja dan tidur disaat kerja dan tidak tercapai secara etis kerja dan bekerja pada saat pimpinan (Soegoto \& Salutondok, 2015) berada di kantor saja. Jadi temuan penelitian ini menunjukkan bahwa disiplin kerja dalam meningkatkan kinerja Balai Latihan Masyarakat Pekanbaru tidak berjalan sesuai dengan harapan.

Harapan disiplin PNS dengan mengunakan alat finger print yang seharusnya memotivasi kerja dan terdcapai pengawasan sejalan dengan penelitian yang telah dilakukan oleh (Kumarayati et al., 2017) bahwa disiplin berpengaruh negatif dan tidak berpengruh terhadap kinerja pegawai hal ini terbukti dalam penelitian ini bahwa Disiplin PNS dalam mengisi finger print tidak meningkatkan kinerja dan motivasinya dalam mencapai kinerja Balai Latihan Masyarakat Pekanbaru. Padahal menurut penelitian (Yudiastra \& Darma, 2015) penggunaan teknologi informasi (Rafika, Budiarto, \& Budianto, 2014) akan meningkatkan kedisiplinan pegawai hal ini memang dipengaruhi oleh pengawasan pemimpin yang kurang terhadap pegawai (Rasyidi et al., 2013) dan kepercayaan karena dengan teknologi akan memberikan informasi apa yang dilakukan dan direncakan oleh pimpinan dan oragnisasi (Syofian \& F.S, 2020) serta 
sanksi yang diberikan seharusnya juga tidak diterima pegawai karena ketidak jujuran pegawai operator dalam melakukan rekapitulasi data kehadiran. Menurut (Saputra et al., 2016) kepemimpinan transformasional yang dibutuhkan dalam mempengaruhi kinerja disiplin dan kinerja pegawai.

Penelitian ini menemukan bahwa kedisiplinan tidak dapat meningkatkan kinerja PNS karena kurangya pengawasan dari pimpinan dan tidak berpengaruhnya sanksi terhadap insentif yang mereka terima walaupun dalam aturan sudah ada sanksi namun dalam pelaksanaan terjadi ketidak jujuran pegawai. Ini sejalan dengan temuan penelitian sebelumnya yang menyatakan bahwa peran pemimpin dalam melaksanakan fungsi kepemimpinannya, pemberian insentif serta kurangnya pengawasan (Rasyidi et al., 2013) akan berdampak kepada kinerja pegawai dan organisasi. Akan tetapi harapan finger print sebagai monitoring data kehadiran sebagai suatu pendekatan strategis dalam peningkatan kinerja pegawai, penilaian kinerja pegawai sesuai dengan harapan kebijakan, organisasi (Junaidi, Anugrah, \& Pancasakti, 2015) dalam penelitian tidak sesuai harapan karena PNS pada Balai Latihan Masyarakat Pekanbaru menjadikan finger print hanya sebagai proses mengisi daftar hadir tanpa pengawasan yang ketat, perubahan perilaku sadar akan tanggungjawab kerja dan kerja etis, setelah melakukan pengisian finger print PNS di Balai Latihan Masyarakat Pekanbaru mengerjakan pekerjaan lain diluar pekerjaan kantor dengan alasan keperluan keluarga, sarapan, pimpinan tidak ditempat dan dukungan pegawai operator dalam manipulasi data isian finger print hal ini terbukti dengan banyak pengawai keluar pada saat jam kantor pada data security pintu pagar kantor, dan temuan saat pimpinan Tugas Luar. Bukti ini diperkuat oleh temuan penelitian bahwa pegawai ada yang istirahat pada saat jam kerja pada Gedung Mes Balai Latihan Masyarakat Pekanbaru.

Penelitian ini berbeda dari penelitian terdahulu yang menemukan bahwa penerapan finger print meningkatkan efektivitas disiplin kerja pegawai dengan peningkatan ketepatan waktu masuk kantor, pulang kantor dan menigkatkan ketaatan aturan tinggi, mengikuti aturan pimpinan dalam menciptakan disiplin kerja dapat dilaksanakan dengan baik dan tanggung jawab yang diberikan mampu dengan baik diselesaikan sesuai target yang ditentukan organisasi (Helmi, Hartutiningsih, \& Djumlani, 2015). Perbedaan yang terlihat bahwa pekerjaan yang dilaksanakan oleh pegawai banyak menumpuk dan tidak selesai sesuai target yang telah ditentukan di Balai Latihan Masyarakat Pekanbaru dan tidak mengerjakan pekerjaan sesuai aturan karena ada temuan bahwa pegawai memanipulasi data kehadiran dan bekerja dikantor saat pimpinan berada dikantor dan tidak rasa tanggungjawab terhadap pekerjaan.

Penelitian terdaulu menemukan faktor-faktor penghambat kedisiplinan pegawai diantaranya faktor kepribadian, faktor lingkungan; sedangkan yang menjadi pendorong kedisiplinan ialah sumber daya aparatur; kesadaran masyarakat; dan sarana dan prasarana (Simatupang, Pabalik, \& Nurchasanah, 2018), (Pangarso \& Susanti, 2016) yang berpengaruh positif terhadap kinerja (Runtunuwu, Lapian, \& Dotulong, 2015)namun berbeda karena penelitian terdahulu dorongan juga berpengaruh terhadap persepsi publik namun dalam penelitian ini tidak tidak ditemukan dorongan kesadaran pegawai dalam melakukan pekerjaan yang mempengaruhi persepsi publik terhadap kedisiplin PNS di Balai Latihan Masyarakat Pekanbaru berdasarkan temuan-temuan penelitian ini dapat dikatakan bahwa dispilin pegawai Balai Latihan Masyarakat Pekanbaru tidak berjalan sesuai dengan atauran dan harapan dalam pencapaian kinerja organisasi.

\section{KESIMPULAN}

Berdasarkan hasil penelitian diatas, maka penulis dapat menarik kesimpulan tentang Disiplin Pegawai Untuk Peningkatan Kinerja Di Balai Latihan Masyarakat Pekanbaru bahwa Disiplin pegawai tidak berjalan optimal dalam meningkatkan kinerja organisasi karena tidak berjalan sesuai aturan, sikap dan perilaku seorang PNS melakukan pelanggaran disiplin dengan berbagai cara tidak bertanggungjawab 
dan ini terjadi karena kurangnya pengawasan pimpinan karena terlalu banyak dan lama Dinas Luar dan ketidak jujuran bawahan dalam rekapitulasi data finger print. Selain itu juga karena mengganggap bahwa finger print hanya sebagai alat isi daftar hadir tanpa merasa bertanggungjawab terhadap kerja pada jam kerja sehingga indikator disiplin; kehadiran, ketaatan kepada aturan kerja, ketaatan pada standar kerja, tingkat kewaspadaan tinggi, bekerja etis tidak berjalan dengan baik karena finger print tidak dijadikan alat disiplin untuk komunikasi pimpinan agar pegawai bersedia mengubah perilakunya sebagai upaya meningkatkan kesadaran sendiri

\section{SARAN}

Berdasarkan hasil penelitian maka peneliti menyarankan agar pimpinan memberikan pemahaman bahwa Disiplin merupakan alat untuk komunikasi pimpinan agar pegawai bersedia mengubah perilakunya sebagai upaya meningkatkan kesadaran dengan kegiatan mensosialisasikan bahwa disiplin dapat meningkatkan kinerja secara sadar PNS. Secara teoritis hasil penelitian disiplin pegawai ini dapat menjadi bahan bagi peneliti berikutnya dalam meneliti disiplin Pegawai Negeri Sipil pada pada Birokrasi Pemerintahan lain.

\section{DAFTAR PUSTAKA}

[1] Helmi, H., Hartutiningsih, \& Djumlani, A. (2015). Efektivitas Disiplin Pegawai Terhadap Penerapan Mesin Absensi Sidik Jari Di Dinas Kependudukan dan Catatan Sipil Kota Balikpapan. Jurnal Administrasi Reform, 3(2), 267-274.

[2] Junaidi, J., Anugrah, L., \& Pancasakti, A. D. (2015). Model Aplikasi Monitoring Sistem Absensi Sidik Jari Sebagai Pendukung Keputusan Untuk Penilaian Kinerja Pegawai. Konferensi Nasional Sistem \& Informatika, 9-10.

[3] Kumarayati, R., Suparta, G., \& Yasa, S. (2017). Pengaruh Motivasi Terhadap Disiplin dan Kinerja Pegawai Pada Sekretariat Daerah Kota Denpasar. Jurnal Ekonomi Dan Bisnis Jagadhita, 4(2), 6375. https://doi.org/10.22225/jj.4.2.224.63-75

[4] Pangarso, A., \& Susanti, P. I. (2016). Pengaruh Disiplin Kerja Terhadap Kinerja Pegawai Di Biro Pelayanan Sosial Dasar Sekretariat Daerah Provinsi Jawa Barat. Jurnal Manajemen Teori Dan Terapan,9(2),145-160. Retrieved from http://e journal.unair.ac.id/index.php/JMTT/article/view/3019

[5] Rafika, A. S., Budiarto, M., \& Budianto, W. (2014). Aplikasi Monitoring Sistem Absensi Sidik Jari Sebagai Pendukung Pembayaran Biaya Pegawai Terpusat Dengan SAP. Creative Communication and Innovative Technology Journal, 8(3), 134-146.

[6] Rasyidi, A., Paranoan, D., \& Djumlani, A. (2013). Variabel-Variabel Yang Mempengaruhi Disiplin Pegawai Pada Dinas Sosial Provinsi Kalimantan Timur. Jurnal Administrasi Reform, 1(2), 341-352. 
[7] Runtunuwu, H. J., Lapian, J., \& Dotulong, L. (2015). Pengaruh Disiplin, Penempatan Dan Lingkungan Kerja Terhadap Kinerja Pegawai Pada Badan Pelayanan Perizinan Terpadu Kota Manado. Jurnal Riset Ekonomi, Manajemen, Bisnis Dan Akuntansi, 3(3), 81-89. https://doi.org/10.35794/emba.v3i3.9313

[8] Saputra, T., Marlinda, P., \& Sufi, W. (2016). Pengaruh Gaya Kepemimpinan Transformasional Terhadap Kinerja Karyawan. Jurnal Niara, 2(1), 54. https://doi.org/10.35697/jrbi.v2i1.64

[9] Setiawan, D. R., \& Yulianti, Y. (2018). Pengaruh Absensi Fingerprint Terhadap Disiplin Kerja Karyawan Pada Pt. Sanbio Laboratories Gunung Putri Kabupaten Bogor. Majalah Ilmiah Bijak, 14(1), 70-81. https://doi.org/10.31334/bijak.v14i1.61

[10] Simatupang, J. H., Pabalik, \& Nurchasanah, S. (2018). Peranan Disiplin Kerja Pegawai Terhadap Efektifitas Pelayanan Masyarakat Di Distrik Sorong Manoi Kota Sorong. Jurnal Ilmu Administrasi Negara, 6(1), 44-51. Retrieved from http://sandyherdians.wordpress.com/2013/04/0

[11] Soegoto, A., \& Salutondok, Y. (2015). Pengaruh Kepemimpinan, Motivasi, Kondisi Kerja Dan Disiplin Terhadap Kinerja Pegawai Di Kantor Sekretariat Dprd Kota Sorong. Jurnal Riset Ekonomi, Manajemen, Bisnis Dan Akuntansi, 3(3), 849-862. https://doi.org/10.35794/emba.v3i3.9659

[12] Saputra, T. (2019). Pengaruh Motivasi Kerja Terhadap Disiplin Kerja Karyawan Pada Hotel Permai Pekanbaru. Jurnal Benefita: Ekonomi Pembangunan, Manajemen Bisnis \& Akuntansi, 4(2), 316-325.

[13] Syofian, \& F.S, H. T. R. (2020). Vill agers ' Satisfaction Indicators on Village Information System in The Front Region. NIARA, 12(2), 34-43.

[14] Yudiastra, P. P., \& Darma, G. S. (2015). Pengaruh Penggunaan Teknologi Informasi, Disiplin Kerja, Insentif, Turnover Terhadap Kinerja Pegawai. Jurnal Manajemen Dan Bisnis, 12(1), 81-99. https://doi.org/10.31843/jmbi

[15] Zahari, M. (2014). Pengaruh Motivasi Terhadap Disiplin Kerja Pegawai Pada Dinas Perindustrian dan Perdagangan Provinsi Jambi. Jurnal Ilmiah Ekonomi Dan Bisnis, 5(1), 41-58. 